\title{
Inhibitors of business intelligence use by managers in public institutions in a developing country: The case of a South African municipality
}

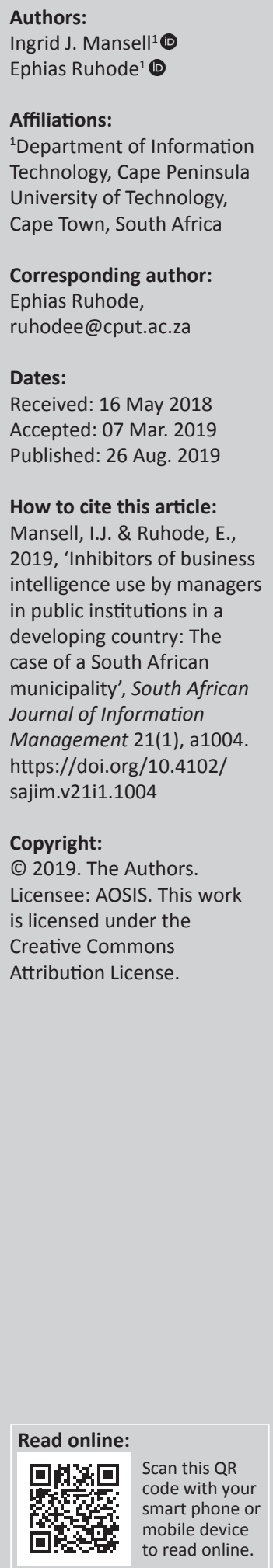

Background: Business intelligence tools play an important role for businesses across all industries for their data and information management solutions. By harnessing the capabilities of business intelligence, companies are able to predict and better meet customer needs. This study investigates factors that inhibit managers' use of business intelligence tools in a public organisation in South Africa, where there has been evidence of a very low uptake of business intelligence tools.

Objective: The objective of this study was to establish factors that inhibit the use of business intelligence and data analytics tools by managers in public organisations. Organisations are likely to lose their competitive advantage and experience a negative impact on efficiency and service delivery if managers do not make use of analytics in strategic decision-making.

Methods: The study utilised both qualitative and quantitative data. Qualitative data were collected from managers through interviews, whilst questionnaires and daily login recordings were used to collect quantitative data. Quantitative data were analysed using statistical methods, whilst qualitative data were analysed by thematic analysis.

Results: The research revealed a wide range of factors that inhibit the use of business intelligence tools by managers. These factors range from personal, system quality, organisational, macro-environmental, behavioural beliefs and attitudes, effort perceptions and social influence to facilitating conditions.

Conclusion: The article provides a comprehensive contextual situation regarding poor use of business intelligence and analytics tools in a large metropolitan public entity. The findings from the organisation under study would be deemed to apply to similar organisations throughout the country.

Keywords: Business intelligence; data analytics; thematic analysis; South Africa; public institutions; developing countries.

\section{Introduction}

Many studies portray business intelligence (BI) as impactful systems for decision-making in organisations, particularly in highly competitive environments (Goldstein 2015; Grubljesic \& Jaklic 2015; Marshall, Mueck \& Shockley 2015). The positive impact is much higher and valuable when relevant technologies that align people, processes and technology are deployed. The advancement of business intelligence and data analytics has enhanced the performance of management systems through uncovering complex patterns and relationships that support strategic planning (Klatt, Schlaefke \& Moeller 2011).

There exist definitional variances of BI in the literature. For the purposes of this study, the definition of Stackowiak, Rayman and Greenwald (2007) is adopted. They define BI as the process of taking large amounts of data, analysing that data and presenting a high-level set of reports that condense the essence of that data into the basis of business actions, enabling management to make fundamental daily business decisions.

This article recognises that public organisations in many developing countries face challenges in adopting business intelligence and data analytics. The challenges relate to business processes and human presence in the information technology (IT) ecosystems (people, process and technology). A public organisation in South Africa is examined to empirically identify the inhibiting factors to business intelligence use by managers at all levels. SAP Business Intelligence (SAP BI) tools have 
been deployed throughout the organisation to provide reports for decision-making in all functional areas, such as finance, human resources, logistics, real estate, customer relations management, supply chain, industry utility solutions, public sector records management, etc. However, based on statistical data of logon details, one can conclude that the usage of analytics amongst managers is low.

It is likely that the organisation will lose its competitive advantage and experience a negative impact on efficiency and service delivery if managers do not make use of analytics in strategic decision-making. From this background, the central question which this study sought to answer is: what are the specific factors that inhibit management usage of analytics in public organisations?

In seeking to answer the research question, the study contributes towards the existing body of knowledge as it provides insights into specific reasons that inhibit management usage of business intelligence and how this impacts management decisionmaking in public organisations.

The article is organised as follows: the next section presents the literature review on business intelligence and the conceptual framework of the study, followed by the methodology adopted. The section that follows presents usage of business intelligence in two phases: quantitative analysis and qualitative analysis. Finally, the article presents the study's recommendations and conclusions.

\section{Literature review}

This section is divided into two subsections, business intelligence and the conceptual framework, which were employed to underpin the study.

\section{Business intelligence and analytics}

According to Klatt et al. (2011:30), the advancement of business analytics has enhanced performance management systems. Good data or analytical tools do not ensure that managers will reach sound decisions. Managers need to be equipped to pose good questions and to interpret the outputs. According to Gartner (2016:n.p.):

$[W]$ ithin the model for business intelligence maturity, there are four levels in which an organisation can be classified in terms of levels of information of increasing value to business strategy.

Figure 1 depicts the questions which, according to Gartner (2016), managers should be able to answer from the use of business intelligence tools:

- Descriptive analytics: what happened? (inform)

- Diagnostic analytics: why did it happen? (explore)

- Predictive analytics: what will happen? (predict)

- Prescriptive analytics: how can we make it happen? (optimise).

Chan and Hernandez (2011:10) argue that it is the responsibility of managers to support and promote the analytical capabilities

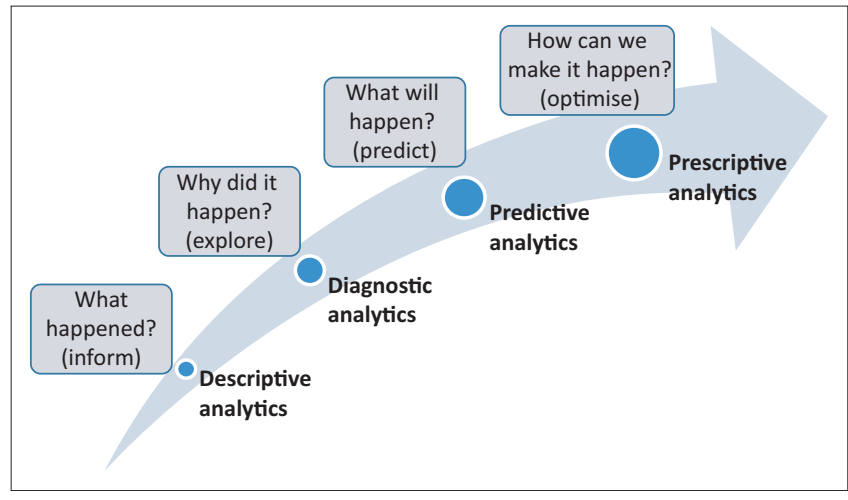

Source: Adapted from Gartner, 2016, A guidance framework for assessing BI maturity, Cape Town, viewed 17 April 2016, from https://www.gartner.com/doc/1405700/guidanceframework-assessing-bi-maturity.

FIGURE 1: Gartner's business intelligence maturity categorisation.

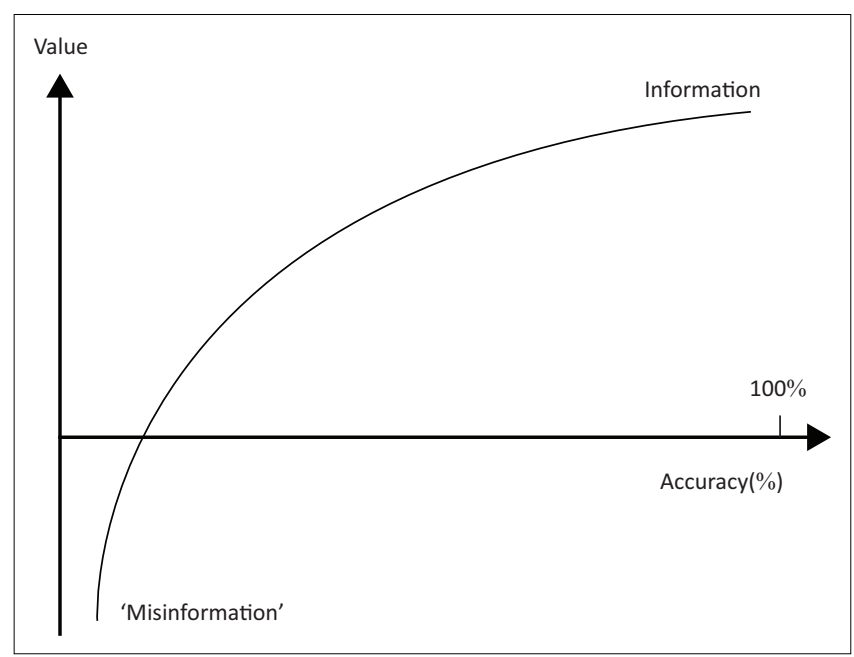

Source: Moody, D. \& Walsh, P., 1999, 'Measuring the value of information: An asset valuation approach', p. 1-17, in 7th European Conference on Information Systems (ECIS'99), Frederiksberg, Denmark.

FIGURE 2: Value increases with accuracy.

and culture within the organisation to ensure sustained growth and success. Within the organisation under study, it is evident that the management complement is not supporting SAP BI, as shown in the low usage of the analytical tool. It has been established by the business improvement section that a gap exists between management accountability and technology. The business improvement team has initiated a management accountability programme in an attempt to address this issue and to create awareness of the critical role of technology amongst managers in their respective areas.

The organisation under study therefore misses out on the benefits that BI brings. Moody and Walsh (1999) drew the relationship between the value of information and the level of its accuracy. Figure 2 shows that the higher the data accuracy, the greater the value an organisation derives from the information.

It has been reported in meetings also that the performance management aspect of the organisation suffers because of poor use of business intelligence. Performance management, according to Swanepoel, Erasmus and Schenk (2008:372$373)$, can be defined as ' $[a]$ process which is focussed on 
TABLE 1: Determinants influencing dimensions of business intelligence usage.

\begin{tabular}{|c|c|c|c|c|c|c|c|}
\hline $\begin{array}{l}\text { Individual } \\
\text { characteristics }\end{array}$ & $\begin{array}{l}\text { Business intelligence } \\
\text { systems quality characteristics }\end{array}$ & $\begin{array}{l}\text { Organisational } \\
\text { factors }\end{array}$ & $\begin{array}{l}\text { Macro-environment } \\
\text { factors }\end{array}$ & $\begin{array}{l}\text { Behavioural beliefs } \\
\text { and attitudes }\end{array}$ & $\begin{array}{l}\text { Effort } \\
\text { perceptions }\end{array}$ & $\begin{array}{l}\text { Social } \\
\text { influence }\end{array}$ & $\begin{array}{l}\text { Facilitating } \\
\text { conditions }\end{array}$ \\
\hline Age & Compatibility & Focus of the customer & Business sector & Relative advantage & Ease of use & Voluntariness & Facilitating conditions \\
\hline Computer literacy & Task-technology fit & Management support & $\begin{array}{l}\text { Competitiveness } \\
\text { of the environment }\end{array}$ & Job relevance & - & Visibility & - \\
\hline Education & Information quality & $\begin{array}{l}\text { User participation in } \\
\text { implementation }\end{array}$ & - & Perceived usefulness & - & Image & - \\
\hline Prior experience & Output quality & $\begin{array}{l}\text { Iterative development } \\
\text { approach }\end{array}$ & - & - & - & - & - \\
\hline Attitude & Relevance & User training & - & - & - & - & - \\
\hline Computer self-efficacy & System quality & Organisational culture & - & - & - & - & - \\
\hline $\begin{array}{l}\text { Personal } \\
\text { innovativeness }\end{array}$ & Complexity & Information culture & - & - & - & - & - \\
\hline Computer anxiety & Accessibility & Change management & - & - & - & - & - \\
\hline \multirow[t]{2}{*}{ Readiness for change } & Triability & Organisational resources & - & - & - & - & - \\
\hline & User interface & Organisational size & - & - & - & - & - \\
\hline
\end{tabular}

Source: Grubljesic, T. \& Jaklic, J., 2015, 'Conceptualization of the business intelligence extended model', Journal of Computer Information Systems 55(3), 77-82. https://doi.org/10.1080/08874417 .2015 .11645774

organisational performance improvement through a number of human resources (HR) processes, including organisational performance'. In the organisation under study, annual targets are set for the key performance indicators but reports show that the performance management levels are always low.

\section{Conceptual framework}

Factors influencing the usage of business analytics can be categorised into the following themes: individual characteristics, business intelligence systems quality, organisational factors, macro-environment factors, behavioural beliefs and attitudes, effort perceptions, social influence and facilitating conditions (Grubljesic \& Jaklic 2015:79). Table 1 lists the possible factors that influence business analytics usage.

According to the conceptual framework, a combination of many factors can contribute to the use of a technology or any tool. This research adopted the framework because of its wide range of factors that are considered. The following section explains the methodology that was employed in the study.

\section{Research design and methodology}

The principal researcher was in direct contact with senior managers in order to fully appreciate how they experience the work environment and their interactions with colleagues. An exploratory (interpretivist) approach was adopted in order to find out what is happening, seek new insights and generate ideas for new research through the participants' perspectives (Ellis, Levy \& Lauderdale 2008:21). Interpretivists argue that human beings are always influenced by the things that are happening in their environment and therefore react accordingly (Du Plooy-Cilliers, Davis \& Bezuidenhout 2015:23-29).

The research approach is inductive, involving thick descriptive data. A mixed-methods research was used, where the aim was for qualitative and quantitative techniques to supplement each other. This approach of using multiple sources of data collection increases the validity and reliability of the study. The qualitative approach draws on interpretive outcomes from interviews and an electronic survey questionnaire. The quantitative approach draws on the daily management logon statistics to the analytical tool and enables the researcher to identify and describe emerging patterns that evolve from the data. The blended approach of qualitative and quantitative techniques confirms and solidifies the results of the study (Du Plooy-Cilliers et al. 2015:33, 204, 228). The research targeted a subset of management, namely, level 4 managers, in the selected organisation. The rationale for selecting this category of managers was that they not only manage staff but also control a budget. This means that they would be required to use analytics to inform decision-making. In addition, the benchmark provided by the Chief Information Officer (CIO) for the recommended logins per month for management level 4 is higher than the other managerial levels. The total number of level 4 managerial posts currently occupied is 524 .

Interviews and an electronic survey questionnaire were used to collect information from the level 4 managers of the organisation as follows:

- An electronic survey questionnaire was distributed to 524 level 4 managers spread across the directorates.

- Interviews were conducted with eight level 4 managers across the directorates.

- Daily analytics login statistics for management were used to establish the percentage of managers using SAP BI. This logon information was obtained via SAP Authorisations. A count of daily logons by management was stored and collated for further analysis.

For the purposes of ethical considerations, BI is a strategic initiative and enhances competitive advantage; hence, the need to keep the identity of the individuals and organisation participating in the study confidential was emphasised. In the same manner, the organisation which formed the empirical home of the research remains anonymous. The information obtained through this study remains strictly confidential. Confidentiality was maintained by means of anonymous inputs, that is, no names were used in the statistical data collection. Participants were informed of the purpose of the research and their consent was sought before commencement of the data collection process. They were assured of confidentiality during the data collection process. Codes were used to identify participants and the directorates of the organisation. If any participant felt uncomfortable, he or she could withdraw from the data collection process. 


\section{Data analysis}

Data were analysed at two levels: quantitative analysis and qualitative analysis. In the former case, the researchers drew conclusions from the data sets and determined the statistical significance of the collected data sets, which contain daily management logon statistics for analytics. The findings from the data sets increase the validity and reliability of the study and complement the qualitative outcomes. In the latter case, qualitative analysis involved the reduction, organisation, interpretation and substantiation of data. The main purpose was to identify themes and patterns embedded in the text. The researchers used thematic analysis with these themes derived from the theoretical framework of Grubljesic and Jaklic (2015). The following themes were explored: individual characteristics, systems quality, organisational factors, macro-environment factors, behavioural beliefs and attitudes, effort perceptions, social influence, facilitating conditions and 'other'.

\section{Statistical data presentation}

The electronic survey questionnaire was distributed to 524 level 4 managers, of which 211 managers responded. Eight level 4 managers were interviewed across the directorates. The interviews complemented the electronic survey questionnaires and provided a deeper understanding of the reason for SAP BI usage and adoption. The results and interpretation are presented next.

\section{Factor analysis}

According to Pallant (2007:179), factor analysis reduces a large set of variables to a smaller use of factors or components by identifying the inter-correlations in the set of variables. Factor analysis was used to determine if there were underlying factors or themes in the data. Six factors were extracted by means of regression.

Factors are similar to 'themes' in qualitative data analysis. In factor analysis, all correlations between all the different items (1-25) are calculated and those that are highly correlated with each other are clustered together in a factor.

Six factors were extracted by means of regression and they related to the theoretical framework. These factors have been used for the thematic analysis as well.

The six factors identified via regression were:

- F1: Management support

- F2: User interface

- F2: System quality

- F4: Iterative development approach

- F5: Job relevance

- F6: User training.

Table 2 lists the questions for each identified factor and the associated themes and sub-themes.

\begin{tabular}{|c|c|c|c|}
\hline Factor & Q.No. & Questions & Theme and Sub-theme \\
\hline \multirow{4}{*}{$\begin{array}{l}\text { F1: Management } \\
\text { support }\end{array}$} & Q19 & Management actively promotes and supports SAP BI. & Social influence $\rightarrow$ Image \\
\hline & Q18 & Information culture is promoted within your directorate. & Organisational factors $\rightarrow$ Information culture \\
\hline & Q17 & The organisation promotes information readiness. & Organisational factors $\rightarrow$ Organisational culture \\
\hline & Q07 & Management promotes the usage of SAP BI. & Organisational factors $\rightarrow$ Management support \\
\hline \multirow[t]{5}{*}{ F2: User interface } & Q15 & The SAP BI e-learning training is easy to find on the portal. & Organisational factors $\rightarrow$ User training \\
\hline & Q04 & Obtaining SAP BI access is straightforward. & System quality characteristics $\rightarrow$ Accessibility \\
\hline & Q05 & It is easy to navigate, search and retrieve information in the SAP BI tool. & System quality characteristics $\rightarrow$ User interface \\
\hline & Q16 & The SAP BI e-learning training is effective. & Organisational factors $\rightarrow$ User training \\
\hline & Q14 & The SAP BI dashboards and reports are easy to understand. & Organisational factors $\rightarrow$ User training \\
\hline \multirow[t]{6}{*}{ F3: System quality } & Q06 & SAP BI will improve service delivery. & Organisational factors $\rightarrow$ Focus on the customer \\
\hline & Q01 & You are comfortable in experimenting with new technology. & Individual characteristics $\rightarrow$ Readiness for change \\
\hline & Q02 & SAP BI information quality is trustworthy. & System quality characteristics $\rightarrow$ System quality \\
\hline & Q20 & SAP BI benefits the public sector. & Macro-environment factors $\rightarrow$ Business sector \\
\hline & Q03 & The performance is good when executing SAP BI reports and dashboards. & System quality characteristics $\rightarrow$ System quality \\
\hline & Q25 & $\begin{array}{l}\text { Analytics usage will improve if placed on an individual's performance } \\
\text { management scorecard. }\end{array}$ & Other \\
\hline \multirow{3}{*}{$\begin{array}{l}\text { F4: Iterative } \\
\text { development } \\
\text { approach }\end{array}$} & Q11 & Your business requirements were adequately met in the newly developed report. & Organisational factors $\rightarrow$ Iterative development approach \\
\hline & Q10 & The turnaround times for the SAP BI developments were satisfactory. & Organisational factors $\rightarrow$ Iterative development approach \\
\hline & Q24 & The technical support for SAP BI issues is good. & Facilitating conditions \\
\hline \multirow[t]{4}{*}{ F5: Job relevance } & Q23 & $\begin{array}{l}\text { You are required to use SAP BI reporting as evidence for day-to-day } \\
\text { business reporting activities. }\end{array}$ & Social influence $\rightarrow$ Visibility \\
\hline & Q22 & $\begin{array}{l}\text { You require the following reporting information to enable management } \\
\text { decisions in } \mathrm{HR} \text {, finance and KPI-related information. }\end{array}$ & Behavioural belief and attitudes $\rightarrow$ Job relevance \\
\hline & Q09 & $\begin{array}{l}\text { You have requested a SAP BI (report or dashboard) to be developed for } \\
\text { your specific business needs. }\end{array}$ & Organisational factors $\rightarrow$ Iterative development approach \\
\hline & Q21 & SAP BI provides your team with a competitive advantage. & $\begin{array}{l}\text { Macro-environment factors } \rightarrow \text { Competitiveness of the } \\
\text { environment }\end{array}$ \\
\hline \multirow[t]{3}{*}{ F6: User training } & Q13 & The SAP BI classroom-based training was effective. & Organisational factors $\rightarrow$ User training \\
\hline & Q12 & You have received SAP BI classroom-based training. & Organisational factors $\rightarrow$ User training \\
\hline & Q08 & $\begin{array}{l}\text { The SAP BI implementation team considered your input when rolling-out } \\
\text { SAP BI in } 2006 \text {. }\end{array}$ & $\begin{array}{l}\text { Organisational factors } \rightarrow \text { User participation in } \\
\text { implementation }\end{array}$ \\
\hline
\end{tabular}

$\mathrm{KPI}$, key performance indicators; SAP BI, SAP business intelligence; F, factor; Q.No., question number; Q., question. 


\section{Cronbach's alpha}

Tavakol and Dennick (2011) affirm that validity and reliability are two fundamental elements in the evaluation of a measurement instrument. Instruments can be conventional knowledge, skill or attitude tests, clinical simulations or survey questionnaires. Instruments can measure concepts, psychomotor skills or affective values. Validity is the extent to which an instrument measures what it is intended to measure. Reliability is the ability of an instrument to measure consistently. Cronbach's alpha is the most widely used with the objective to measure reliability. The Cronbach's alpha values in Table 3 are all above 0.7 , which is deemed to be reliable.

According to Tavakol and Dennick (2011), the number of test items, item inter-relatedness and dimensionality affect the value of alpha. Acceptable values of alpha range from 0.70 to 0.95. A low value of alpha could be because of a low number of questions and poor inter-relatedness between items. A low alpha should be revised or discarded. If alpha is too high, it may suggest redundancy. A maximum alpha value of 0.90 is recommended.
Table 3 shows the 'loadings' of each of the items on the factor.

\section{Thematic analysis of qualitative data}

Ruhode (2016) states that themes come both from the data (an inductive approach) and from the investigator's prior theoretical understanding of the phenomenon under study (an a priori approach). In a priori approach, themes come from the characteristics of the phenomenon being studied as understood by the researcher. A researcher's values, theoretical orientations and personal experiences can be sources of themes in a priori approach (Ruhode 2016:3). In this study, a priori approach was used.

\section{Thematic analysis of the interview documents}

Table 4 shows the identified dominant themes and their descriptions. These themes were identified in the theoretical framework, which underpin the interview questions. The themes are: individual characteristics, system quality

TABLE 3: Factor analysis to determine underlying themes.

\begin{tabular}{|c|c|c|c|c|c|c|c|c|}
\hline \multirow[t]{2}{*}{ Q.No. } & \multirow[t]{2}{*}{ Pattern matrix $\dagger$} & \multicolumn{6}{|c|}{ Factor } & \multirow{2}{*}{$\begin{array}{l}\text { Cronbach's } \\
\text { alpha }\end{array}$} \\
\hline & & 1 & 2 & 3 & 4 & 5 & 6 & \\
\hline Q19 & Management actively promotes and supports SAP BI. & 0.923 & - & - & - & - & - & \multirow{4}{*}{0.85} \\
\hline Q18 & Information culture is promoted within your directorate. & 0.722 & - & - & - & - & - & \\
\hline Q17 & The organisation promotes information readiness. & 0.684 & 0.323 & - & - & - & - & \\
\hline Q07 & Management promotes the usage of SAP BI. & 0.660 & - & - & - & - & - & \\
\hline Q06 & SAP BI will improve service delivery. & - & 0.766 & - & - & - & - & \multirow{6}{*}{0.832} \\
\hline Q01 & You are comfortable in experimenting with new technology. & - & 0.608 & - & - & - & - & \\
\hline Q02 & SAP BI information quality is trustworthy. & - & 0.569 & - & - & - & - & \\
\hline Q20 & SAP BI benefits the public sector. & - & 0.542 & - & - & - & - & \\
\hline Q03 & The performance is good when executing SAP BI reports and dashboards. & - & 0.451 & - & - & - & - & \\
\hline Q25 & $\begin{array}{l}\text { Analytics usage will improve if placed on an individual's } \\
\text { performance management scorecard. }\end{array}$ & - & 0.345 & - & - & 0.312 & & \\
\hline Q15 & The SAP BI e-learning training is easy to find on the portal. & - & - & 0.842 & - & - & - & \multirow{5}{*}{0.745} \\
\hline Q04 & Obtaining SAP BI access is straightforward. & - & - & 0.744 & - & - & - & \\
\hline Q05 & It is easy to navigate, search and retrieve information in the SAP BI tool. & - & - & 0.733 & - & - & - & \\
\hline Q16 & The SAP BI e-learning training is effective. & - & - & 0.618 & - & - & - & \\
\hline Q14 & The SAP BI dashboards and reports are easy to understand. & - & - & 0.443 & - & - & - & \\
\hline Q11 & $\begin{array}{l}\text { Your business requirements were adequately met in the newly } \\
\text { developed reports. }\end{array}$ & - & - & - & 0.975 & - & - & \multirow{2}{*}{0.824} \\
\hline Q10 & The turnaround times for the SAP BI development were satisfactory. & - & - & - & 0.816 & - & - & \\
\hline Q24 & The technical support for SAP BI issues is good. & - & - & - & - & - & - & - \\
\hline Q23 & $\begin{array}{l}\text { You are required to use SAP BI reporting as evidence for day-to-day } \\
\text { business reporting activities. }\end{array}$ & - & - & - & - & 0.840 & - & \multirow{4}{*}{0.712} \\
\hline Q22 & $\begin{array}{l}\text { You require the following reporting information to enable management } \\
\text { decisions in } \mathrm{HR} \text {, finance and KPI-related information. }\end{array}$ & - & - & - & - & 0.554 & - & \\
\hline Q09 & $\begin{array}{l}\text { You have requested a SAP BI (report or dashboard) to be developed for } \\
\text { your specific business needs. }\end{array}$ & - & - & - & - & 0.459 & - & \\
\hline Q21 & SAP BI provides your team with a competitive advantage. & - & - & - & - & 0.450 & & \\
\hline Q13 & The SAP BI classroom-based training was effective. & - & - & - & - & - & 0.841 & \multirow{3}{*}{0.747} \\
\hline Q12 & You have received SAP BI classroom-based training. & - & - & - & - & - & 0.618 & \\
\hline Q08 & $\begin{array}{l}\text { The SAP BI implementation team considered your input when rolling-out } \\
\text { SAP BI in } 2006 \text {. }\end{array}$ & - & - & - & - & - & 0.338 & \\
\hline
\end{tabular}

Note: Extraction method: maximum likelihood; rotation method: Promax with Kaiser normalisation.

$\uparrow$, Rotation converged in seven iterations.

$\mathrm{KPI}$, key performance indicators; SAP BI, SAP business intelligence; Q.No., question number; Q., question. 
characteristics, organisational culture, macro-environment factors, behavioural beliefs and attitudes, effort perception, social influence, facilitating conditions and 'other'.

Individual characteristics deal with age and the readiness for change of the managers. Organisational factors focus on management support of SAP BI, user participation in the implementation, user training and the iterative development approach of SAP BI reports. System quality characteristics are concerned with information quality, system quality, accessibility and the user interface of the SAP BI tool. Organisational culture deals with information readiness, information culture and change management and macroenvironment factors within the relevant business sector and competitiveness of the environment. Effort perception is the user's view on how easy the tool is to use. Social influence deals with visibility and image of the managers, whilst facilitating conditions with the technical support and report creation for SAP BI. The 'other' theme deals with placing SAP $\mathrm{BI}$ on the managers Information Technology Pillars Model (IPM) scorecard. These themes are described in Table 4.

Eight respondents across the directorates were interviewed. The interview duration was between 10 and $15 \mathrm{~min}$. Table 5 provides an analysis of feedback from the interviews and identified relevant themes.

The general consensus from the interviews is that managers are not using SAP BI. Managers appreciate the value of reporting; however, they are not extracting the information themselves. Many of the managers are receiving reporting

TABLE 4: Dominant emerging themes.

\begin{tabular}{ll}
\hline Theme & Description \\
\hline Individual characteristics & Age, readiness for change \\
Organisational factors & $\begin{array}{l}\text { This deals with focus on the customer, management } \\
\text { support, user participation in the implementation, } \\
\text { user training and the iterative development approach }\end{array}$ \\
System quality characteristics & $\begin{array}{l}\text { This deals with information quality, system quality, } \\
\text { accessibility and the user interface of the SAP BI tool }\end{array}$ \\
Organisational culture & $\begin{array}{l}\text { Information readiness, information culture and } \\
\text { change management }\end{array}$ \\
Macro-environment factors & $\begin{array}{l}\text { Relevant business sector, competitiveness of the } \\
\text { environment }\end{array}$ \\
Behavioural beliefs and & Relative advantage and job relevance \\
attitudes & Ease of use \\
Effort perception & Visibility and image \\
Social influence & Technical support \\
Facilitating conditions & $\begin{array}{l}\text { Placing analytics usage on an individual's } \\
\text { performance management scorecard }\end{array}$ \\
Other &
\end{tabular}

information from their assistants or clerks. They are not using the tool frequently and, as a result, find the user interface difficult and cumbersome to use. They resort, therefore, to assistance from their staff, as the latter can extract the required information far more quickly than they can. The managers stated that the SAP BI training needs to be customised to their specific environment. The current training approach is more generic and deals with navigation around the tool. Customising the training would result in tailored specific needs for an area, that is, financial reporting, human resources reporting or property management reporting. Data quality is a concern for the managers using SAP BI. Often, the SAP BI batch is completed with errors, resulting in data being incorrect. This casts doubt on the reliability of the data and results in managers using SAP R/3 instead as the main source of information. Reporting from $\mathrm{R} / 3$ is often slow because of the volume of data and results in managers not being able to make timely decisions or react quickly to changing circumstances. Some of the managers felt that performance of the reports was an issue, which resulted in managers not using SAP BI. The managers had different views on placing reporting on managers' IPM scorecard. Some felt strongly that this would enforce usage of the tool, whilst others felt that it would be counter-productive as managers would merely login to the tool to be 'viewed' as using SAP BI.

\section{Ethical consideration}

Ethical clearance for the main study (thesis) was obtained from the Cape Peninsula University of Technology and consent was obtained from the municipality in the study.

\section{Recommendations and conclusion The role of analytics in the organisation and management's perceptions of analytics}

Seventy-seven per cent of managers perceive that the organisation promotes information readiness. Management places high value on reporting and appreciates the impact it has on the strategic direction of the organisation. This finding is supported by responses to the electronic survey questionnaire, which indicated that $61 \%$ of managers confirm that information culture is promoted within the directorates. Of the managers, 57\% agreed that SAP BI benefits the public sector and $69 \%$ reported that they needed to report on HR, Finance and KPI-related information. What has been discovered through the interview process is that a certain percentage of managers are not drawing the SAP BI reports

TABLE 5: Mapping of themes to interview documents

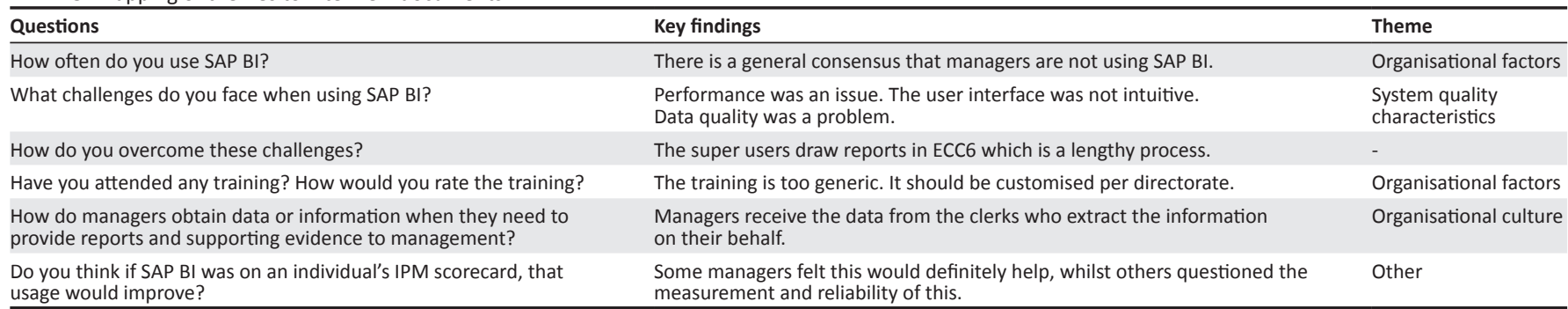

SAP BI, SAP business intelligence; IPM, Information Technology Pillars Model. 
themselves, but are requesting their assistants or clerks to fulfil this requirement. As a result, the statistics for management usage of SAP BI is skewed and an average of $7 \%$ of level 4 managers are using the SAP BI tool.

\section{Specific factors that inhibit the managers' usage of analytics}

This study has shown that SAP BI usage amongst level 4 managers is low and provides reasons for the low usage. The key problem areas that have been established are data quality, user training and the SAP BI user interface.

\section{Recommendations Individual characteristics}

Individual characteristics deal with age and the readiness for change. The average age of the level 4 managers is 49 years. This cohort typically is not comfortable with technology. The recommendation is to arrange refresher training interventions focussed on their specific needs. A blended approach of classroom-based training and e-learning training is recommended. Level 4 managers require hand-holding until they are comfortable with the tool. Classroom-based training will be beneficial, whilst they can recap using the e-learning lessons in their offices.

\section{Organisational factors}

Organisational factors deal with management support of SAP BI, user participation in the implementation, user training and the iterative development approach.

It is recommended that a process owner should be established for analytics to instil a stronger management support base for SAP BI. This individual needs to be at an executive level and should be a champion to promote analytics culture within the organisation. A further recommendation is crafting a SAP BI strategy with a holistic view on technology, processes and human imperatives to ensure successful adoption, usage and sustainability of the tool.

It is further recommended that training should be tailored per directorate to address specific reporting requirements per area. Currently, training is more generic and benefits will be achieved if the training model is adapted accordingly.

\section{System quality characteristics}

System quality characteristics deal with information quality, system quality, accessibility and the user interface of the SAP BI tool.

Firstly, it is recommended that SAP BI batch monitoring should be implemented to ensure information and system quality. This will require $24 / 7$ monitoring. If a process chain fails, a BI developer is contacted after to address the problem, specifically around month-end and SAP month-end. Improved data quality will result in improved trust by the business in the reports.
Secondly, it is recommended that the IT department put measures in place to ensure data integrity by monitoring $\mathrm{BI}$ batch processes and ensuring that alerts are in place if a process fails. For businesses to adopt analytics, data integrity is critical to instil confidence amongst users of SAP BI.

A third recommendation is that performance tuning should be undertaken, such as the use of SAP Hana, to create significant performance gains for the users, leading to renewed enthusiasm for the usage of the tool as long delays will no longer be an issue.

The last recommendation is to address the user interface by empowering managers to use the tool by offering refresher SAP BI training that meets specific needs and requirements.

\section{Organisational culture}

Organisational culture deals with information readiness, information culture and change management. The previous recommendation under organisational factors, that is, to establish a process owner, is equally important for organisational culture. Establishing a process owner for analytics and with constant executive support for the tool will change the reporting culture within the organisation over time. This ensures that the right information is available at the right time to managers and will create a foundation for information readiness and uptake of the SAP BI tool.

\section{Macro-environment factors}

Macro-environment factors deal with the relevant business sector and competitiveness of the environment. The organisation is a public sector concern and focusses on customer, not profit. Profitable organisations need to have a competitive edge and reporting is an enabler for them to remain successful. It is recommended that the organisation re-orientates its culture towards using analytics. The information culture of the public sector requires a mind shift for managers to realise that analytics is an enabler to assist in supporting the customer more efficiently and to improve service delivery. This shift could be established once a process owner has been established and could result in changing the organisational culture towards analytical capabilities.

\section{Effort perception}

Effort perception is the users' view on how easy the tool is to use. Managers expressed that they struggled with the user interface. Focussed and customised refresher SAP BI training is recommended.

\section{Social influence}

Social influence deals with visibility and image. The establishment of a process owner for SAP BI is essential 
as mentioned previously in organisational factors and organisational culture. This will set the tone at the top and other managers will follow suit. The information and organisational culture towards reporting will mature over time because of the executive support and buy-in for the tool.

\section{Facilitation conditions}

Facilitation conditions deal with the technical support and report creation for SAP BI. Currently, the development of a SAP BI report is a two-pronged approach in that the BI developer's and functional business analysts' input is required. The functional analysts are involved with project and support work and capacity is an issue. This is impacting the lengthy timelines to create reports, which is frustrating the users. It is recommended that different personnel deal with support and project-related work. This should eliminate delays in report delivery timelines.

\section{Other}

The 'other' theme deals with placing SAP BI on a manager's IPM scorecard. Once a process owner has been established, this recommendation can possibly be introduced into the organisation. SAP BI usage can be monitored by the number of logins to SAP BI in a month. Statistics can also be set up on frequently used reports and dashboards. Only what gets managed, gets done. Behaviour will eventually change and an information culture will be instilled into the organisation.

\section{Conclusion}

In conclusion, analytics is the enabler of success for the organisation under study. Managers need to make informed and timely decisions based on facts to stay abreast of competition, improve service delivery, have awareness of changing markets and to streamline processes. Analytics is a driver of achieving these objectives and ensuring success and sustainability for the organisation. It has been established that the usage of analytics is low within the organisation under study and there are specific factors that contribute to managers not using the analytical tools. Interviews and electronic survey questionnaires have highlighted the main causes of low usage. The key areas to address include establishing a process owner at an executive level and crafting an analytics innovation strategy that includes processes, technology and people. The organisation has focussed on technology. However, it has neglected the people component. People are critical to the success of any technology as the value of the toolsets lies in the actual usage, which increases return on investment. To balance the people component, customised training must be implemented. To establish confidence in data quality, batch monitoring must be implemented with immediate effect. These initiatives could change the organisation and information culture over time and entrench analytics, creating a flourishing and successful organisation.

\section{Acknowledgements Competing interests}

The authors declare that they have no financial or personal relationships which may have inappropriately influenced them in writing this article.

\section{Author's contributions}

This study originated from I.J.M.'s master's degree thesis under the sole supervision of E.R.

\section{Funding}

This research received no specific grant from any funding agency in the public, commercial, or not-for-profit sectors.

\section{Data availability statement}

Data sharing is not applicable to this article as no new data were created or analysed in this study.

\section{Disclaimer}

The views and opinions expressed in this article are those of the authors and do not necessarily reflect the official policy or position of any affiliated agency of the authors.

\section{References}

Chan, T.C. \& Hernandez, J., 2011, 'CRM analytics: Shifting the balance', Customer Relationship Management, (August), 10.

Du Plooy-Cilliers, F., Davis, C. \& Bezuidenhout, R., 2015, Research matters, Juta \& Company Ltd, Cape Town.

Ellis, T.J., Levy, Y. \& Lauderdale, F., 2008, 'Framework of problem - Based research - A guide for novice researchers on the development of a research - Worthy problem', The International Journal of an Emerging Transdiscipline 11, 17-33. https://doi. org/10.28945/438

Gartner, 2016, A guidance framework for assessing BI maturity, Cape Town, viewed 17 April 2016, from https://www.gartner.com/doc/1405700/guidance-frameworkassessing-bi-maturity.

Goldstein, J., 2015, 'Digital technology demand is transforming HR', Workforce Solutions Review pp. 28-30, viewed 29 September 2016, from https://issuu.com/ ihrimpublications/docs/wsr_jan2015_all.

Grubljesic, T. \& Jaklic, J., 2015, 'Conceptualization of the business intelligence extended model', Journal of Computer Information Systems 55(3), 72-82. https:// doi.org/10.1080/08874417.2015.11645774

Klatt, T., Schlaefke, M. \& Moeller, K., 2011, 'Integrating business analytics into strategic planning for better performance', Journal of Business Strategy 32(6), 30-39. https://doi.org/10.1108/02756661111180113

Marshall, A., Mueck, S. \& Shockley, R., 2015, 'How leading organizations use big data and analytics to innovate', Strategy \& Leadership 43(5), 32-39. https://doi. org/10.1108/SL-06-2015-0054

Moody, D. \& Walsh, P., 1999, 'Measuring the value of information: An asset valuation approach', p. 1-17, in 7th European Conference on Information Systems (ECIS'99), Frederiksberg, Denmark.

Pallant, J., 2007, A step by step guide to data analysis using SPSS for Windows, 3rd edn., Open University Press, New York.

Ruhode, E., 2016, 'E-government for development: A thematic analysis of Zimbabwe's information and communication technology policy documents', The Electronic Journal of Information Systems in Developing Countries 73(7), 1-15. https://doi. org/10.1002/j.1681-4835.2016.tb00532.x

Stackowiak, R., Rayman, J. \& Greenwald, R. 2007, Oracle data warehousing and business intelligence solutions, Wiley Publishing, Inc, Indianapolis, IN.

Swanepoel, B., Erasmus, B. \& Schenk, H., 2008, South African human resource management theory \& practice, 4th edn., Juta \& Co Ltd, Cape Town.

Tavakol, M. \& Dennick, R., 2011, 'Making sense of Cronbach's alpha', Internationa Journal of Medical Education 2, 53-55. https://doi.org/10.5116/ijme.4dfb.8dfd 